Article

\title{
Excellent Thermally Conducting Ni Plating Graphite Nanoplatelets/Poly(phenylene sulfone) Composites for High-Performance Electromagnetic Interference Shielding Effectiveness
}

\author{
Zhang Chen ${ }^{1,2}$, Ting Yang ${ }^{2}$, Lin Cheng ${ }^{3}$ and Jianxin $\mathrm{Mu}^{2, *}$ \\ 1 Shenzhen WOTE Advanced Materials Co., Ltd., Shenzhen 518000, China; chenzhang1983823@126.com \\ 2 Key Laboratory of High Performance Plastics, Ministry of Education, National \& Local Joint Engineering \\ Laboratory for Synthesis Technology of High Performance Polymer, College of Chemistry, Jilin University, \\ Changchun 130012, China; yangting1988@jlu.edu.cn \\ 3 Jilin University Special Plastics Co., Ltd., Changchun 130000, China; chenglin21@mails.jlu.edu.cn \\ * Correspondence: Jianxin_mu@jlu.edu.cn; Tel.: +86-135-0433-7983
}

\section{check for}

updates

Citation: Chen, Z.; Yang, T.; Cheng, L.; Mu, J. Excellent Thermally Conducting Ni Plating Graphite Nanoplatelets/Poly(phenylene sulfone) Composites for HighPerformance Electromagnetic Interference Shielding Effectiveness. Polymers 2021, 13, 3493. https:// doi.org/10.3390/polym13203493

Academic Editors: Artur Pinto and Fernão D. Magalhães

Received: 17 September 2021

Accepted: 2 October 2021

Published: 12 October 2021

Publisher's Note: MDPI stays neutral with regard to jurisdictional claims in published maps and institutional affiliations.

Copyright: (c) 2021 by the authors. Licensee MDPI, Basel, Switzerland. This article is an open access article distributed under the terms and conditions of the Creative Commons Attribution (CC BY) license (https:/ / creativecommons.org/licenses/by/ $4.0 /)$.
Abstract: First, nickel particles were deposited on the surface of graphite nanoplatelets to fabricate highly conductive GnPs@Ni core-shell structure hybrid fillers via electroplating. The modified GnPs were blended with polyphenylene sulfone via the solution blending method, followed by the hot-pressing method to achieve high thermally conducting GnPs@Ni/PPSU composites for high performance electromagnetic interference effectiveness. The results showed that in-plane and through-plane thermal conductivity of the composite at the $40 \mathrm{wt} \%$ filler loading could reach $2.6 \mathrm{Wm}^{-1} \mathrm{~K}^{-1}$ and $3.7 \mathrm{Wm}^{-1} \mathrm{~K}^{-1}$, respectively, which were 9.4 and 20 times higher than that of pure PPSU resin. The orientation degree of fillers was discussed by XRD and SEM. Then, heat conduction data were fitted and analyzed by the Agari model, and the heat conduction mechanism was further explored. The testing results also demonstrated that the material exhibited good conductivity, electromagnetic shielding effectiveness and superior thermal stability. Overall, the GnPs@Ni/PPSU composites had high thermal conductivity and were effective electromagnetic shielding materials at high temperatures.

Keywords: graphene; thermal properties; composites

\section{Introduction}

With the advent of the fifth-generation mobile communication and artificial intelligence technology, electronic devices are stepping towards miniaturization and high integration, which makes the power consumption of electronic products increase and the heat dissipation difficult, seriously limiting the development of the next generation of novel electronic components [1-3]. Meanwhile, the radiation pollution of electromagnetic wave is becoming increasingly prominent, which leads to the decrease of the service life of sensitive electronic components and endangers human health [4]. Traditional thermal conductive materials (TC) and electromagnetic interference (EMI) materials, such as aluminum foil and copper foil, cannot meet the satisfaction of modern communication, intelligent electronic equipment, automobile and consumer electronics, due to their high density and poor corrosion resistance. Recently, incorporating thermal conductive fillers, such as metal powders [5], carbon nanotubes [6], graphite [7], graphene [8] and boron nitride [9] into polymer matrix to fabricate high $\lambda$ polymeric composites are widely used in the field of industry, microelectronics, energy, aerospace and so on due to their light weight, chemical corrosion resistance, impact resistance and easy processing [10-12].

Metal powders, such as, $\mathrm{Ag}, \mathrm{Cu}$, and $\mathrm{Ni}$, with excellent electrical and thermal conductivity, are widely applied in the preparation of high heat conduction and electromagnetic 
shielding materials. Zhou et al. [13] incorporated Al particles in poly(vinylidene fluoride) (PVDF) matrix by the melt blending method. The $\lambda$ value of the Al/PVDF composite with $60 \mathrm{vol} \% \mathrm{Al}$ reached approximately $1.74 \mathrm{Wm}^{-1} \mathrm{~K}^{-1}$, nearly seven times that of the original PVDF matrix. Rivière et al. [14] prepared a series of thermally conductive AgNP/PEEK nanocomposites, and the obtained $\lambda$ value of the AgNP/PEEK nanocomposite with $8 \mathrm{vol} \%$ Ag was significantly enhanced to $0.49 \mathrm{Wm}^{-1} \mathrm{~K}^{-1}$. However, it is still a great challenge to fabricate ideal thermal conductive materials at lower filler loading. Moreover, it has high density and high cost. Recently, researchers have prepared core-shell particles, such as Agplated graphite nanosheets and nickel-plated carbon fiber. Hybrid particles with core-shell structure have advantage over traditional carbon materials and metal powder [15-17]. For example, Li et al. [18] successfully fabricated Ni-CF/PEEK composites, of which thermal and electrical conductivity can reach up to $1.9 \times 10^{4} \mathrm{~S} / \mathrm{m}$ and $0.65 \mathrm{Wm}^{-1} \mathrm{~K}^{-1}$, respectively. In addition, Ni-plated graphite can improve the interfacial compatibility between the fillers and polymer matrix, further enhancing the bonding strength. Additionally, the developed material not only represents both excellent electrical and thermal conductivity, but is also lightweight and low cost [19]. Hence, Ni-plated graphite is widely used in manufacturing conductive composites. Electroless plating, a new metal surface treatment technology, is widely drawing the attention of scientific researchers because of its simple technology, and energy saving and environmental protection characteristics. Therefore, the electroplating has a wide range of applications in protection performance, decoration, and other functions. The uniform metal plating layer could improve the corrosion resistance and service life of the product.

Graphite nanoplatelets are two-dimensional fillers with high aspect ratio, which are composed of graphene flakes with different stacking layers. GnPs have elicited substantial applications in the field of efficient heat management materials because of its extreme inplane $\lambda$ (approximately $3000 \mathrm{Wm}^{-1} \mathrm{~K}^{-1}$ ) and low interfacial thermal resistance [20,21]. Liu and co-workers [22] reported the epoxy composites filled with particular structure cigarette filter-templated graphene. The perpendicular $\lambda$ value of the epoxy composites was enhanced to $1.2 \mathrm{Wm}^{-1} \mathrm{~K}^{-1}$, four times higher than that of in-plane $\lambda$ value $\left(0.298 \mathrm{Wm}^{-1} \mathrm{~K}^{-1}\right)$. However, weak interactions between pure GnPs and polymer matrix as well as intensive Van der Waals forces between graphite nanoplatelets make it prone to aggregation, leading to poor interfacial interactions and, consequently, high thermal resistance [21,23]. In order to solve the mentioned problems, treating by the surface modification, including covalent and non-covalent method, is usually carried out [24]. Improving the interaction of GnPs with polymer matrix without sacrificing the near-perfect structure is still a challenging issue to fabricate high $\lambda$ composites.

In light of the findings advanced by our previous research team members [18], the surface modification of nano graphite sheet is carried out by chemical plating technology, and nickel nano particles are deposited on the surface of graphite nanoplatelets to prepare the electrical and thermal conductive fillers GnPs@Ni with core-shell structure. The above hybrid fillers were then mixed with polyphenylene sulfone solution, followed by hot-pressing to prepare GnPs@Ni/PPSU composites. The chemical composition and microstructure of GnPs@Ni and its composites samples with different filler loading were characterized. The thermal conductivity, the orientation of layered fillers, and the effects of $\mathrm{Ni}$ were investigated. Additionally, EMI shielding, EC value and thermal stability were analyzed.

We hope that by adding high thermal conductivity filler, the polymer will have good thermal conductivity and electromagnetic shielding performance, so as to expand the application of polymers in the field of electronic communication and promote the realization of the goal of replacing steel with plastic. 


\section{Materials and Fabrication}

\subsection{Materials}

The PPSU (powder, 800 mesh) of density $1.25 \mathrm{~g} \mathrm{~cm}^{-3}$ was purchased from Jilin University Special Plastics Co., Ltd. (Changchun, China). The GnPs (powder, 99.5\%) of density $0.6 \mathrm{~g} \mathrm{~cm}^{-3}$ was purchased from Chengdu Organic Chemicals Co., Ltd. (Chengdu, China). Trisodium citrate dihydrate $\left(\mathrm{C}_{6} \mathrm{H}_{5} \mathrm{Na}_{3} \mathrm{O}_{7} \cdot 2 \mathrm{H}_{2} \mathrm{O}, \mathrm{AR}\right)$, sodium hypophosphite $\left(\mathrm{NaH}_{2} \mathrm{PO}_{2} \cdot \mathrm{H}_{2} \mathrm{O}, \mathrm{AR}\right)$ and $\mathrm{N}, \mathrm{N}$-Dimethylformamide (DMF, AR 99.5\%) were obtained from Macklin Biochemical Technology Co., Ltd. (Shanghai, China). Hydrochloric acid ( $\mathrm{HCl}, 37 \%)$ and nickel sulfate $\left(\mathrm{NiSO}_{4} \cdot 6 \mathrm{H}_{2} \mathrm{O}, \mathrm{AR}\right)$ were received from Tianjin Chemical Reagent $\mathrm{Co}$., Ltd. (Tianjin, China). The Stannous chloride dihydrate $\left(\mathrm{SnCl}_{2}, \mathrm{AR}\right)$ and Palladium chloride $\left(\mathrm{PdCl}_{2}, \mathrm{AR}\right)$ was purchased from Aladdin Biochemical Technology Co., Ltd. (Shanghai, China).

\subsection{Preparation of GnPs@Ni Hybrids}

Herein, electroless nickel plating was utilized to prepare GnPs@Ni functional particles with core-shell structure. First, the graphite nanoflakes were extracted with acetone to remove the surface impurities, then filtered and dried at $100^{\circ} \mathrm{C}$ in the vacuum oven. The sensitizing solution was prepared with $25 \mathrm{~g} \mathrm{SnCl}_{2}, 10 \mathrm{~mL}$ concentrated $\mathrm{HCl}$ and $1 \mathrm{~L} \mathrm{H}_{2} \mathrm{O}$. An amount of $1 \mathrm{~g} \mathrm{GnPs}$ were added into the above solution, treated by ultrasonication for $30 \mathrm{~min}$ and filtered. Subsequently, the sensitized $\mathrm{GnPs}$ were added into the activation solution that was composed of $0.05 \mathrm{~g} \mathrm{PdCI}_{2}, 0.01 \mathrm{~mL}$ concentrated $\mathrm{HCl}$ and $100 \mathrm{~mL} \mathrm{H}_{2} \mathrm{O}$ with ultrasonication for $30 \mathrm{~min}$, followed by filtering and washing. The composition of electroless plating bath was $20 \mathrm{~g} \mathrm{NiCl} 2 \cdot 6 \mathrm{H}_{2} \mathrm{O}, 30 \mathrm{~g} \mathrm{C}_{6} \mathrm{H}_{5} \mathrm{Na}_{3} \mathrm{O}_{7} \cdot 2 \mathrm{H}_{2} \mathrm{O}, 40 \mathrm{~g} \mathrm{NaH} \mathrm{PO}_{2} \cdot \mathrm{H}_{2} \mathrm{O}$ and $1 \mathrm{~L} \mathrm{H}_{2} \mathrm{O}$, adjusting $\mathrm{pH}$ value in the range of 4.9. The pretreated $\mathrm{GnPs}$ were dispersed into the electroplating liquid via ultrasonication at $88^{\circ} \mathrm{C}$. The reaction time was $2 \mathrm{~h}$. Next, the mixture was separated by vacuum assisted filtration through PTFE membrane and washed repeatedly until the filtrate became colorless. The black powders with slight metallic luster (GnPs@Ni) were obtained.

\subsection{Preparation of GnPs@Ni/PPSU Composites}

The prepared Gnps@Ni was added to the beaker containing DMF, and the dispersion of Gnps@Ni was prepared with a concentration of $5 \mathrm{~g} / \mathrm{L}$, then treated by ultrasonication for $2 \mathrm{~h}$. A certain amount of PPSU was added to the fully dispersed solution subsequently to prepare a solution containing Gnps@Ni $10 \mathrm{wt} \%, 20 \mathrm{wt} \%, 30 \mathrm{wt} \%$, and $40 \mathrm{wt} \%$, respectively. The above solution was stirred at room temperature for $12 \mathrm{~h}$. Then, the mixed solution was poured into a large amount of cold deionized water under stirring. After stirring for $6 \mathrm{~h}$, the solution was filtered and washed with a large amount of deionized water. The obtained filter cake was cut into small pieces and dried in a vacuum oven to constant weight. GnPs@Ni/PPSU composites were beaten into powder with a high-speed mixer and hot-pressed at $280{ }^{\circ} \mathrm{C}$ and $30 \mathrm{Mpa}$. Figure 1 presents the corresponding schematic diagram of the fabrication for the GnPs@Ni/PPSU nanocomposites.

\subsection{Characterization}

The equation used to calculate the thermal conductivity of materials is shown as follows:

$$
\lambda=\alpha \cdot C_{p} \cdot \rho
$$

The $\rho, \alpha$ and $C_{p}$ in the formula represent density, thermal diffusion $\left(\mathrm{mm}^{2} \mathrm{~s}^{-1}\right)$, and specific heat capacity, respectively. The composite sheet obtained by hot-pressing was made into a small disc with a thickness of $0.8 \mathrm{~mm}$ and a diameter of $12.5 \mathrm{~mm}$, then thermal diffusion coefficient of the material at $20{ }^{\circ} \mathrm{C}$ was measured by laser flasher (LFA 467 was made by Netzsch in Germany). DSC 821e (Made by Mettler Toledo in Switzerland) was used to measure the heat capacity of the material. The density was measured by a hydrometer. Network analyzer (N5244A PNA-X was made by Agilent in America) was used to measure the electromagnetic shielding effectiveness. Keithley2450 was used to 
determine the electrical conductivity of the material at $25^{\circ} \mathrm{C}$. We used DIL 806 (Made by TA instruments in America) to measure the thermal expansion coefficient of the material at temperature range from 30 to $180^{\circ} \mathrm{C}$, and the heating rate was set to $5^{\circ} \mathrm{C} \mathrm{min}^{-1}$. We carried out thermogravimetric analysis of the sample with TGA/DSC1 in nitrogen atmosphere; the temperature range was 100 to $800{ }^{\circ} \mathrm{C}$, and the heating rate is $10^{\circ} \mathrm{C} \mathrm{min}-1$. The chemical composition of the material was determined by XRD (XRD-6000 was made by Shimadzu Corporation in Japan) and X-ray photoelectron spectroscopy (RSCAKAB250X was made by ThermoVG America). The Micromorphology of the materials was captured by transmission electron microscopy (TEM, Jeol2100 was made by Jeol in Japan) and scanning electron microscopy (SEM, NOVA NANOSEM 450 was made by FEI corporation in America).

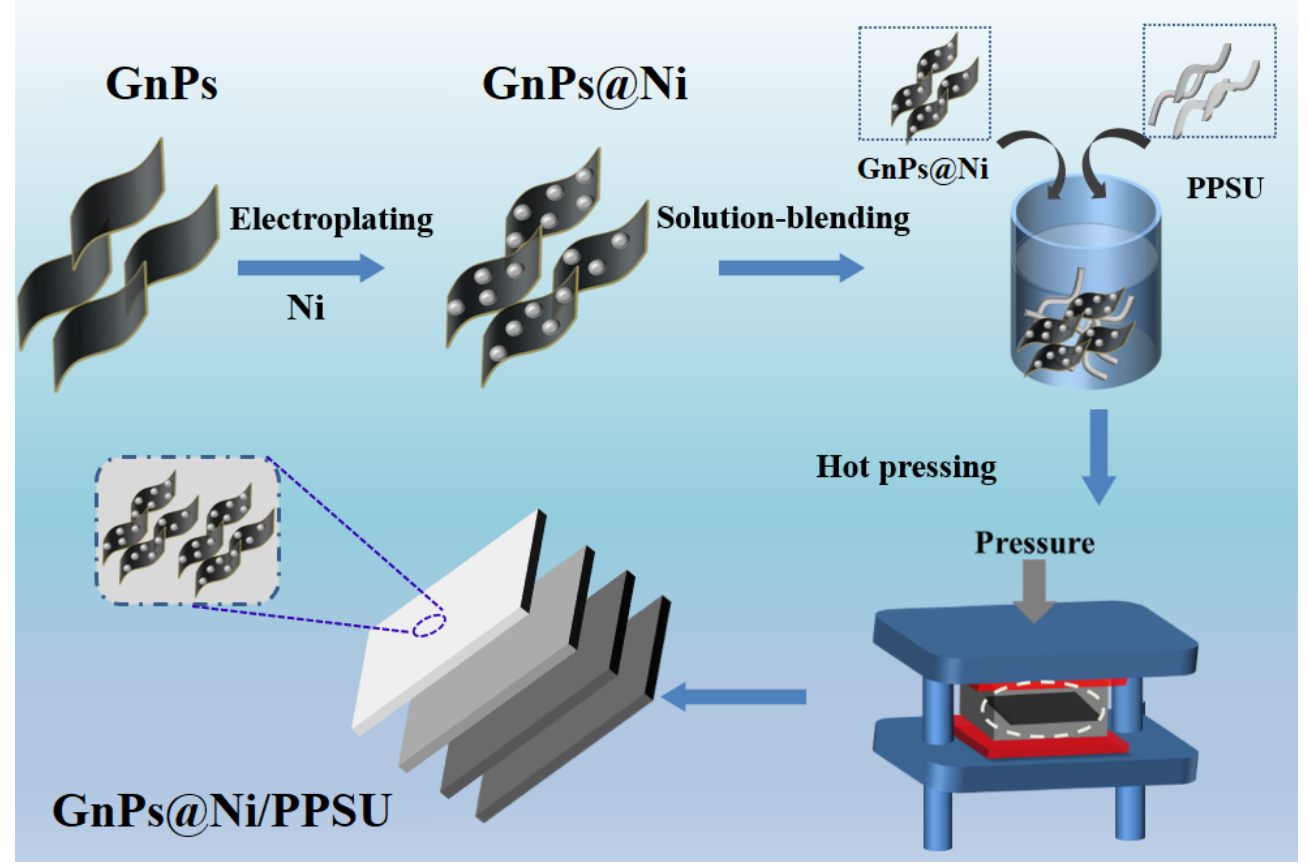

Figure 1. The corresponding schematic diagram of the fabrication for the GnPs@Ni/PPSU nanocomposites.

\section{Results and Discussion}

\subsection{Chemical Composition of GnPs@Ni-MWCNTs Hybrid Filler}

Herein, XPS and XRD spectrum were performed to investigate chemical composition of the modified graphite nanoplatelets after electroless nickel plating process. As shown in Figure $2 \mathrm{a}-\mathrm{c}$, the peaks at $281.8 \mathrm{eV}$ and $535.4 \mathrm{eV}$ attributed to $\mathrm{C} 1 \mathrm{~s}$ and $\mathrm{O} 1 \mathrm{~s}$, respectively. After treatment, the appearance of new characteristic peaks of Ni 2p in GnPs@Ni at binding energies of $855.3 \mathrm{eV}$ preliminarily proves that nickel particles were deposited on the surface of graphite nanoplatelets successfully. The elemental scan of Ni $2 p 4 / 3$ and Ni $2 p 5 / 3$ core level peaks of the functional filler being centered at $855.4 \mathrm{eV}$ and $873.1 \mathrm{eV}$ can be observed, respectively. It is noteworthy that the $\mathrm{Ni} 2 \mathrm{p}$ peak had two oxidative satellite peaks, which were derived from trivalent nickel of $\mathrm{Ni}(\mathrm{OH})_{3}$ in the coating and finally transformed into $\mathrm{NiOOH}$ [25]. Therefore, there are more than one kind of Ni-containing compounds on the surface of graphite nanoplates: Ni, Ni-P alloy, Ni oxides and hydroxides, which further explained the enhancement in intensity of $\mathrm{O} 1 \mathrm{~s}$ peak in Figure $2 \mathrm{~b}$. In order to further determine the crystal structure of Ni particles and the related reaction process involved, the $\mathrm{XRD}$ was carried out. Figure $2 \mathrm{~d}$ illustrated that aside from the characteristic peaks of GnPs $\left(26.3^{\circ}\right)$, the peaks at $44.8^{\circ}$ and $52.1^{\circ}$ corresponded to the $\mathrm{Ni}(111)$ and $\mathrm{Ni}(200)$ crystal face, respectively. Moreover, the additional diffraction peaks were located at $2 \theta=40.6^{\circ}$ and 51. $6^{\circ}$, corresponding to Bragg diffraction peaks of Pd (111) and Sn (110) planes [26]. It proved that Pd and Sn nanoparticles appeared on the surface of the prepared GnPs@Ni, 
indicating that the Sn metal particles were not completely wrapped by Pd particles. During the whole process, as autocatalytic active centers, most of the Pd particles were coated by Ni nanoclusters; meanwhile, the catalytic ability of Sn was much lower than that of Pd. Therefore, it cannot work as a growth center to participate in the chemical reaction to generate Ni nanoparticles [25].
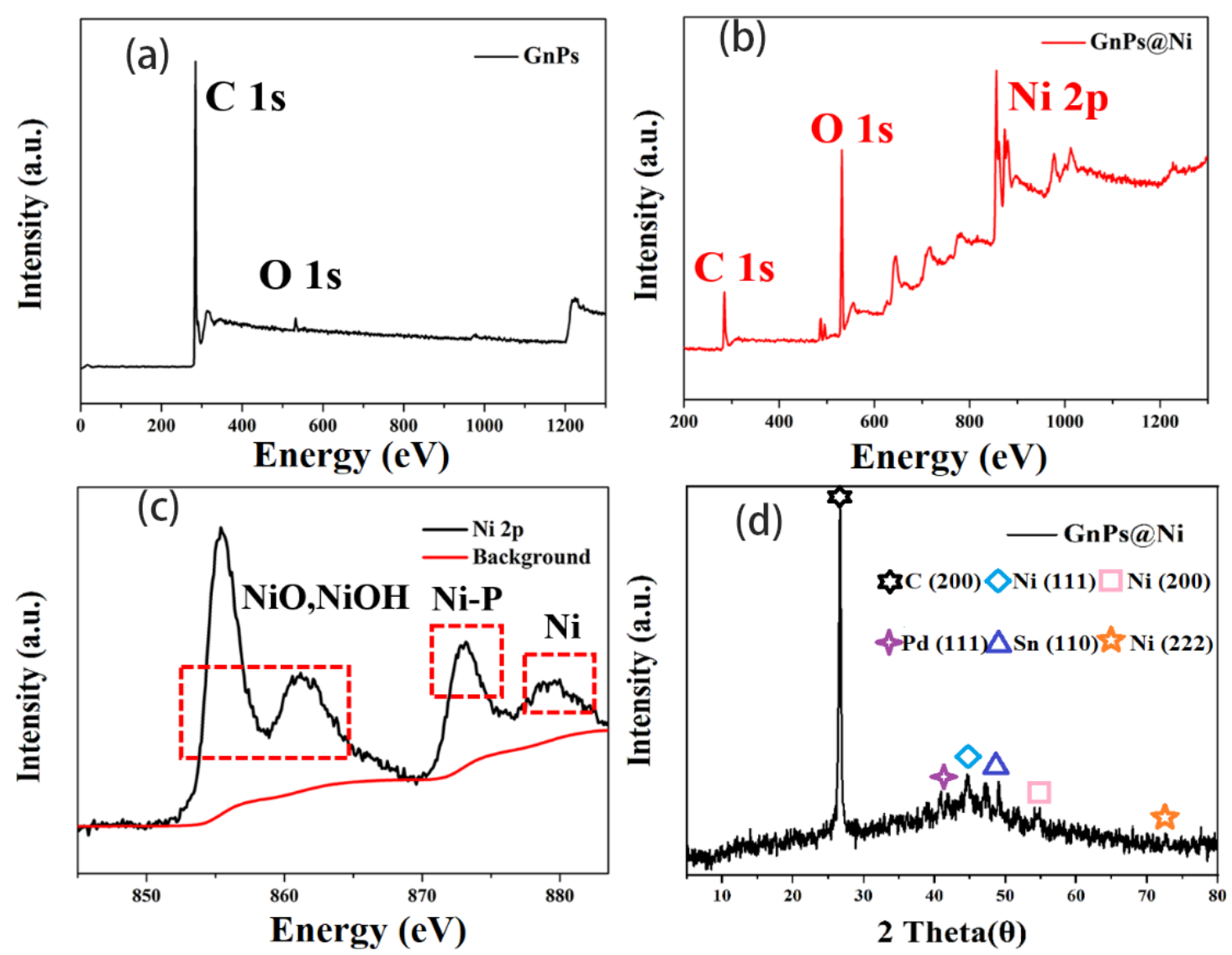

Figure 2. The XPS wide-scan spectrum of GnPs (a) and Gnps@Ni (b); XPS spectra of Ni 2p in the GnPs@Ni (c); the XRD pattern of Gnps@Ni (d).

\subsection{Morphology of GnPs@Ni-MWCNTs Hybrid Filler}

To visualize the Ni-plated graphite nanoplatelets morphology, scanning electron microscopy (SEM) and transmission electron microscopy (TEM) were employed. As demonstrated in Figure $3 a, c$, it is clear that the graphite nanosheets had a folded and slightly wrinkled morphology composed of a small amount of single-layer graphene. After chemical deposition, many spherical nickel nanoclusters were observed to have appeared on the surface of GnPs, but the particle size was slightly uneven. In addition, it could be seen from TEM that Ni nanoparticles were distributed uniformly, and there was no obvious agglomeration on the surface of GnPs. The distribution of nickel loaded on graphite nanoplatelets was observed to in Figure 3e-g via EDX analysis, and the green part represents the distribution range of nickel elements, thus it is observed that the distribution of nickel in the surface of $\mathrm{GnPs} @ \mathrm{Ni}$ was uniform, which is consistent with the observed phenomena in SEM and TEM. In addition, Figure $3 \mathrm{~h}$ illustrates that GnPs surface mainly contained $\mathrm{C}, \mathrm{O}, \mathrm{P}, \mathrm{Ni}, \mathrm{Pd}$ and $\mathrm{Sn}$, accounting for 55.45, 21.25, 10, 12.83, 0.23 and $0.24 \mathrm{wt} \%$. 

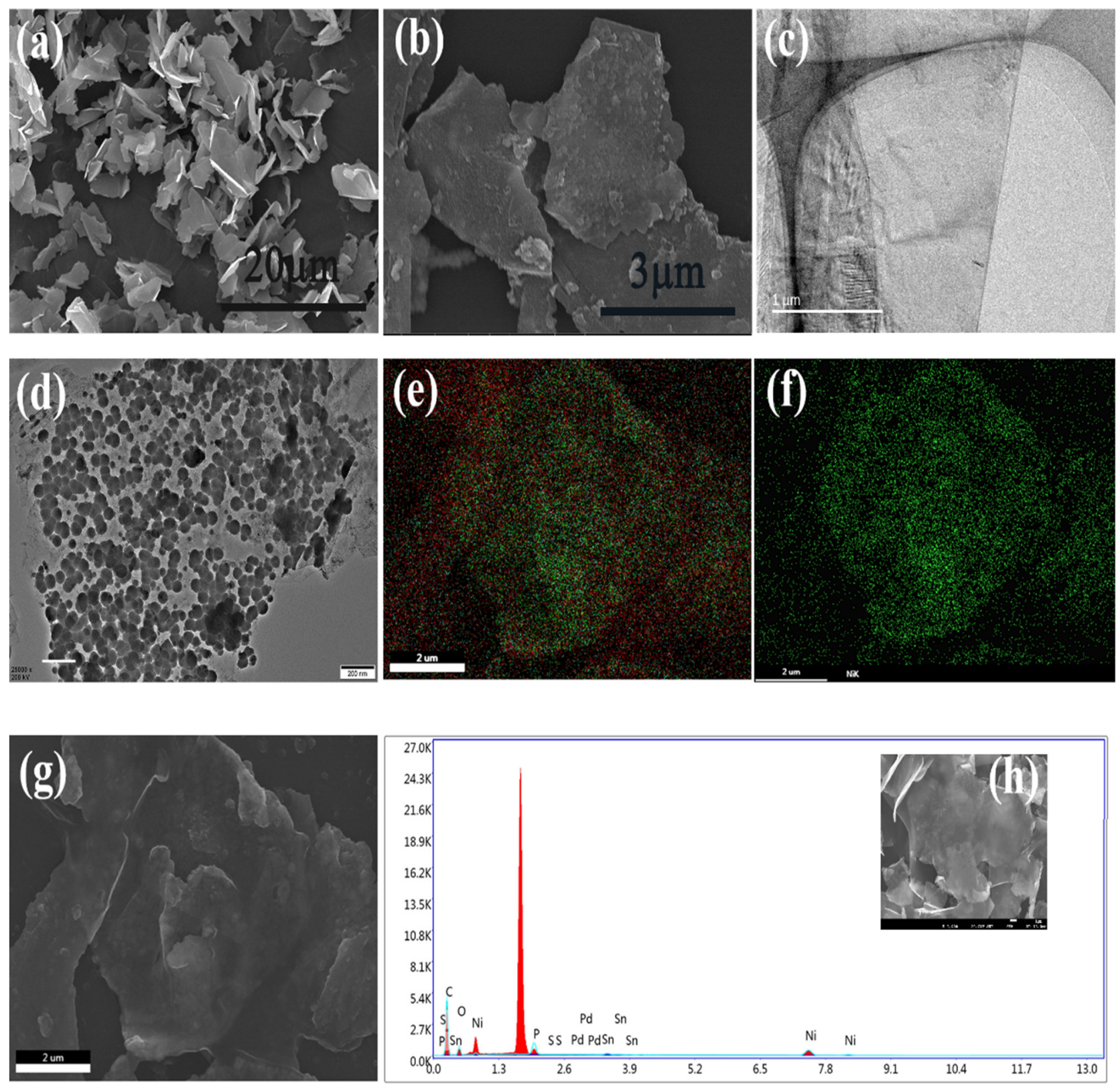

Figure 3. The SEM images of GnPs (a) and GnPs@Ni (b); TEM images of GnPs (c) and GnPs@Ni (d); the background and mapping of GnPs@Ni (e-g); the EDX analysis of GnPs (h).

\subsection{Thermal Conductivity of GnPs@Ni/PPSU Composites}

An upward trend in the TC value of the GnPs@Ni/PPSU composites was seen with the filler content increasing in Figure 4.

For example, in-plane and through-plane $\lambda$ value of the developed composites can reach up to 2.8 and $3.7 \mathrm{Wm}^{-1} \mathrm{~K}^{-1}$ at $40 \mathrm{wt} \%$ filler loading, respectively, indicating the thermal conductivity enhancement (TCE) of modified composites were 10 and 14 times higher than that of pure PPSU matrix. Additionally, it is notable that conduction of heat currents showed obviously anisotropic inside the composites materials, which is mainly caused by the selective arrangement of thermally conducting fillers in the PPSU matrix. Herein, X-ray diffraction (XRD) patterns of the prepared GnPs@Ni/PPSU composites materials containing different amounts of $\mathrm{GnPs} @ \mathrm{Ni}$ was utilized to analyze the orientation degree of the layered fillers in the PPSU matrix qualitatively and roughly. As seen in Figure $3 b$, there are mainly three diffraction peaks at $2 \theta=26.5^{\circ}, 45.6^{\circ}$ and $54.7^{\circ}$, attributed to the (002), (101) 
and (004) crystallographic planes of GnPs@Ni functional fillers, respectively. The orientation degree of GnPs@Ni can be obtained by the ratio of diffraction peak intensity between (002) and (101) crystal surface (I (002))/(I (101)). The research shows that the filler is easier to be oriented in the horizontal direction under the influence of gravity $[27,28]$. When the amount of filler increases, the ratios were $2.5,4.3,6.9$ to 7.2 , respectively, which indicates that the layered GnPs@Ni is mainly distributed along the (002) crystal surface [29,30]. Furthermore, according to the SEM spectra, it was found that with the increase of filler content in the GnPs@Ni/PPSU composites, multilayer graphene nanoflakes tended to be distributed along horizontal direction, which was consistent with the above XRD spectrum. Due to the large aspect ratio and good flexibility, layered shaped fillers such as graphene, $\mathrm{BN}$ and Mxene, tend to selectively locate in the horizontal direction of the composites during the hot-pressing process under the effect of gravity [31,32]. The intrinsic thermal conductivity of GnPs in the vertical direction is rather low (about $6 \mathrm{Wm}^{-1} \mathrm{~K}^{-1}$ ).
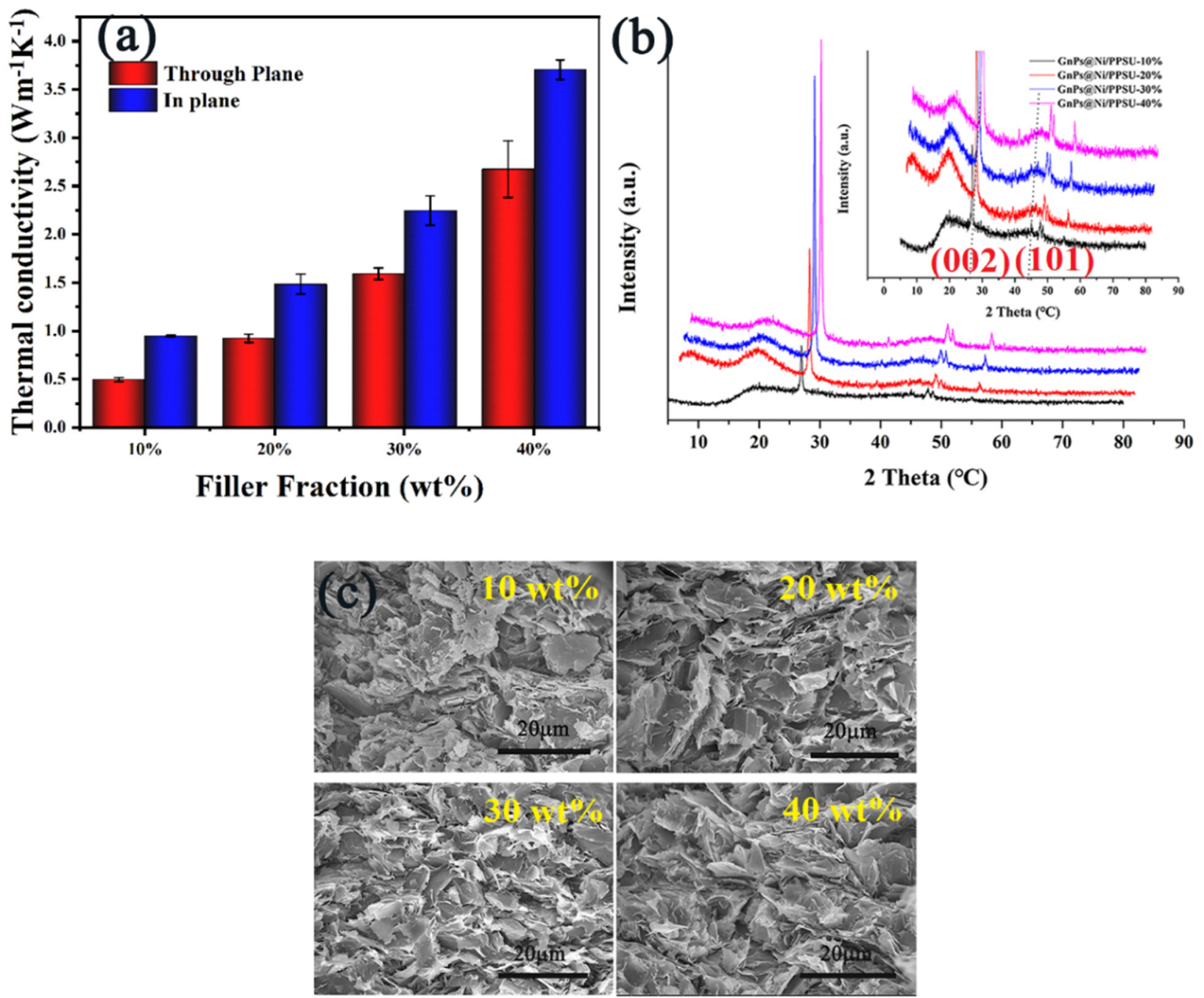

Figure 4. The in-plane and through plane thermal conductivity (a), along with XRD spectrum (b) of the GnPs@Ni/PPSU composites; the SEM images of the developed composites at different filler loading (c).

As illustrated in Figure 5, the PPSU matrix acts as heat flow barriers between the fillers, resulting in serious phonons scattering in the vertical direction of composites. On the contrary, in the horizontal direction is the adjacent bridged layered filler, which is beneficial to construct consecutive thermally conductive networks. According to the thermally conductive path theory, the heat currents tend to transfer along the pathways with low 
interfacial thermal resistance in the polymeric composites, leading to the heat currents transmitting much faster along the horizontal direction. Hence, the thermal conduction presented obvious anisotropy in the composites on the macro level.
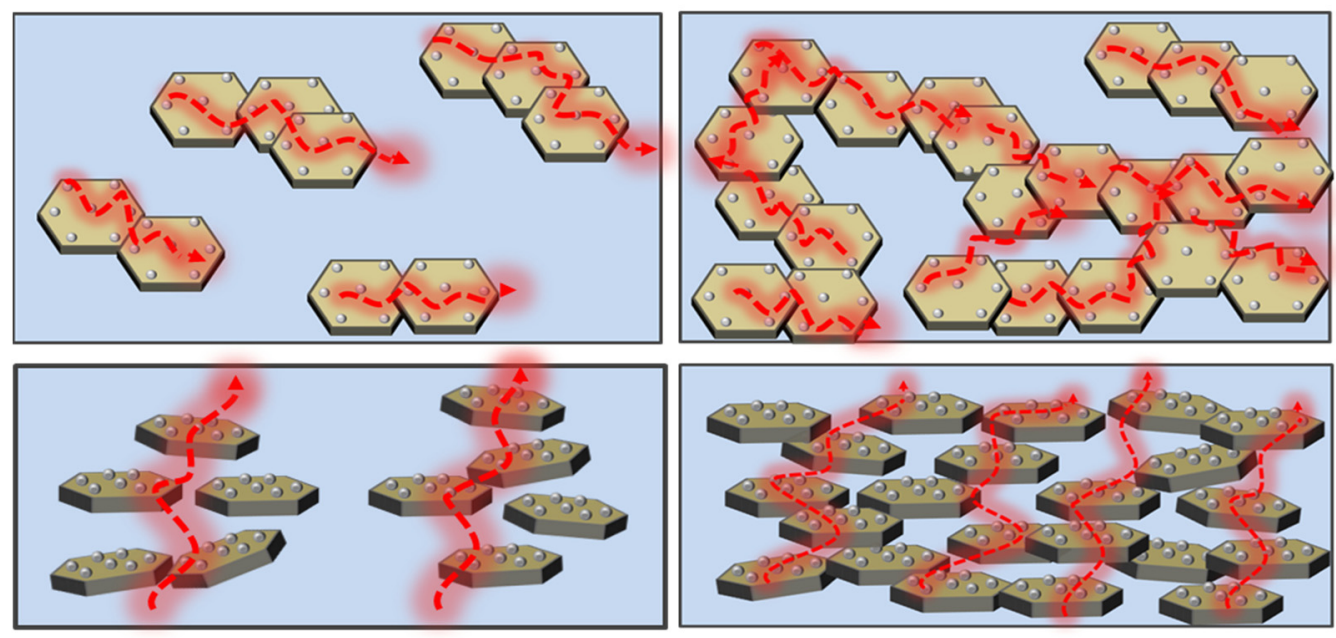

Figure 5. Schematic diagram of ideal heat conduction mechanism of composite materials.

Figure 6 comparatively shows the $\lambda$ value of GnPs@Ni/PPSU and GnPs/PPSU, and the Agari model is utilized to analyze the effects of Ni layer on the thermal conductivity enhancement. When the filling content was low, both GnPS@Ni/PPSU and GnPs/PPSU composites exhibited similar thermal conductivity. Nevertheless, the $\lambda$ value of the composite is significantly higher than that of GnPs/PPSU when the filler amount is beyond $10 \mathrm{vol} \%$. Subsequently, the Agari model was used to weigh up the capability of two functional fillers of forming heat conductive networks in the nanocomposites.

$$
\log \lambda_{\mathrm{c}}=\mathrm{V}_{\mathrm{f}} \mathrm{C}_{2} \log \lambda_{\mathrm{f}}+\left(1-\mathrm{V}_{\mathrm{f}}\right) \log \left(\mathrm{C}_{1} \lambda_{\mathrm{m}}\right)
$$

where $V_{f}, \lambda_{f}, \lambda_{m}, \lambda_{c}$ represented volume percentage of fillers, thermal conductivity of fillers, matrix and developed composite, respectively, with a view to assess those impact for dispersion of conductive fillers for thermal management. The variables for $C_{1}$ and $C_{2}$ are presented. $C_{1}$ is an element reflecting the impact for crystallinity and crystal size of matrix on the thermal conduction capacity of composite. When $C_{1}<1$, the filler will affect the structure of the matrix, thus affecting the thermal conductivity of the material. On the contrary, when $C_{1}>1$, it will not affect the thermal conductivity. $C_{1}$ will approach 1 under ideal condition, which proposes that secondary structure of polymer was slightly influenced by the addition of fillers, especially for the thermal conductivity. $C_{2}$ represents the contact tightness of filler particles, that is, the ability of forming a heat conduction network. In the specification, $C_{2}$ is $0 \sim 1$, but in practical application, the greater the $C_{2}$ value, the composites, therefore the stronger the ability to form a heat conduction network. As shown in Table 1, first, the result shows that the incorporation of GnPs@Ni and GnPs has no influence on the secondary structure of PPSU. Instead, compared to GnPs/PPSU, $\mathrm{C}_{2}$ was improved obviously in the GnPs@Ni/PPSU, indicating the ability of GnPs to form thermal conductive pathways was effectively enhanced after electroless plating [33,34]. In contrast to covalent modification, surface modification by chemical deposition will not destroy the crystal structure and physical properties of thermal conductive fillers. This may be because the introduction of the metal layer can enlarge the contact area between the fillers, leading to the increment in the amount of the heat conductive pathways. 


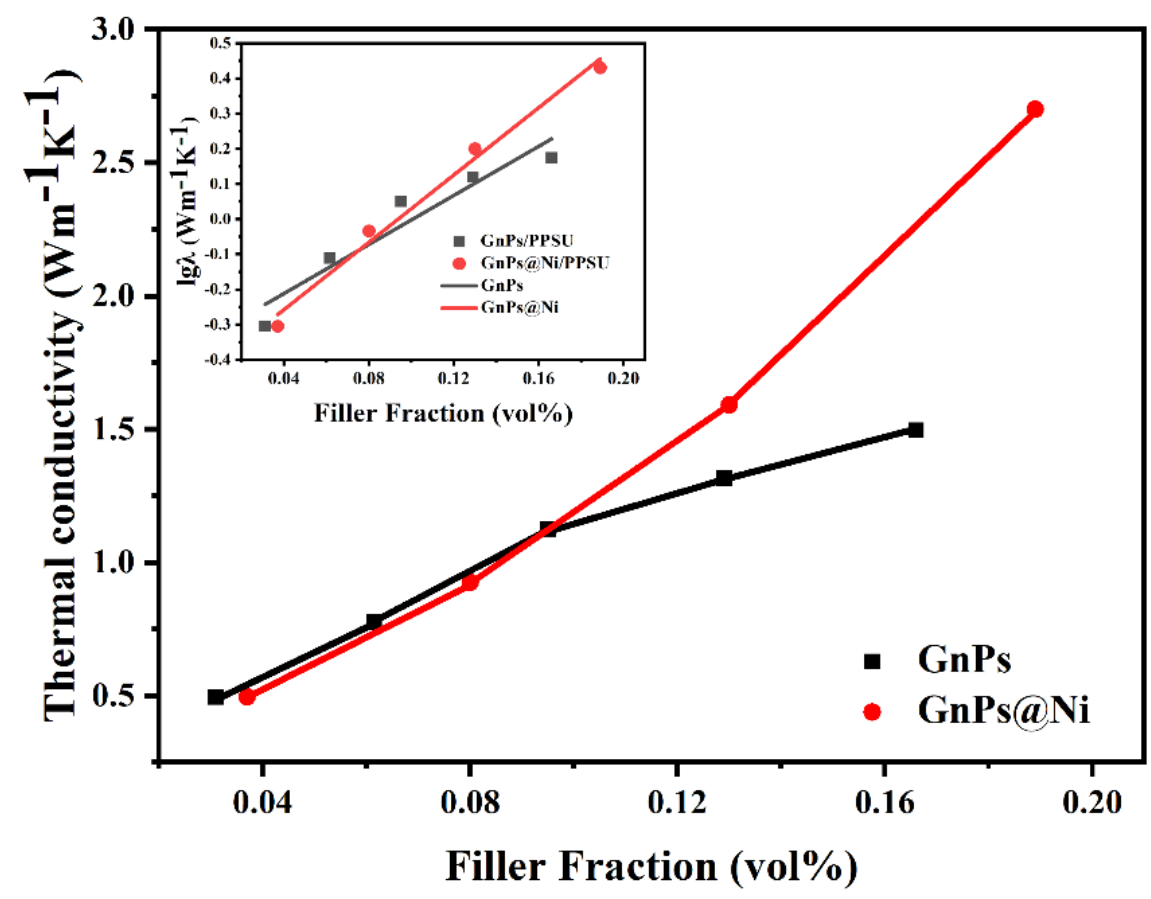

Figure 6. The fitted curve of TC value of the GnPs/PPSU and GnPs@Ni/PPSU composites based on Agari model.

Table 1. The comparison of $\mathrm{C}_{1}$ and $\mathrm{C}_{2}$ of GnPs/PPSU and GnPs@Ni/PPSU.

\begin{tabular}{ccc}
\hline & $\mathrm{C}_{\mathbf{1}}$ & $\mathrm{C}_{\mathbf{2}}$ \\
\hline $\mathrm{GnPs} / \mathrm{PPSU}$ & 1.76 & 1.24 \\
$\mathrm{GnPs} @ \mathrm{Ni} / \mathrm{PPSU}$ & 1.42 & 1.4 \\
\hline
\end{tabular}

\subsection{EMI Shielding Performance of GnPs@Ni-MWCNTs/PPSU Composites}

Based on the plane electromagnetic wave conduction theory advanced by Schelkunoff, perfect conductive network structures are one of prerequisites to obtain high EC value and electromagnetic shielding effectiveness $[35,36]$. The EC value of the GnPs@Ni/PPSU composites is presented in Figure 7a. The EC rose sharply with the increase of filler amount, verifying that successive conductive path has been established. The EC value was achieved to $128.3 \mathrm{~S} / \mathrm{m}$ at $40 \mathrm{wt} \%$ filler loading, which is nearly 15 orders of magnitude higher than that of pure PPSU (around 10-13). The EMI shielding effectiveness of the prepared PPSU composites on frequency ranging from 8.4 to $12.8 \mathrm{GHz}$ can be seen in Figure $7 \mathrm{~b}-\mathrm{d}$. With the amount of functional particles GnPs@Ni increasing, the total shielding effectiveness (SET) and absorption efficiency (SEA) were significantly boosted, contrarily, the reflection efficiency (SER) showed a slight improvement from around an average of 2.5 to $6.8 \mathrm{~dB}$. The maximum SET, SEA and SER reached 7.1, 38.3 and $42.9 \mathrm{~dB}$, respectively, at the $40 \mathrm{wt} \%$ filler loading, which far exceeds the commercial demand $(20 \mathrm{~dB})$. The transmission $(\mathrm{T})$, absorption $(\mathrm{A})$ and reflection efficiency $(\mathrm{R})$ of the composites are calculated according to the electromagnetic shielding formula. Consequently, the reflectivity increases from 0.48 to 0.79 with the increase of filler content as shown in 3.7 (d) $[25,37]$. Therefore, it can be inferred that the modified GnPs@Ni/PPSU composite was high-performance reflection-dominated electromagnetic shielding material [38]. The likely mechanism could be explained as follows. When the electromagnetic wave reaches the surface of the composite, since GnPs@Ni/PPSU composites have very high conductivity, the impedance mismatch of the interphase between air and composites gives rise to large amounts of electromagnetic waves to be reflected. As mentioned, reflectivity holds a large proportion of the whole shielding effectiveness. Meanwhile, owing to GnPs@Ni fillers having weak magnetism, once the residual electromagnetic waves enter interior of materials, they will be absorbed 
and exhausted, effectively achieving the purpose of attenuating the electromagnetic wave. Therefore, it is difficult to penetrate the material $[18,25,35]$.

(a)

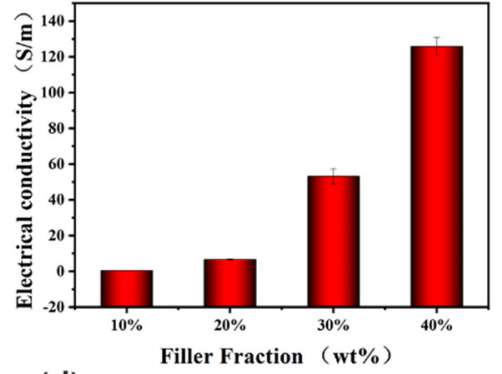

(d)

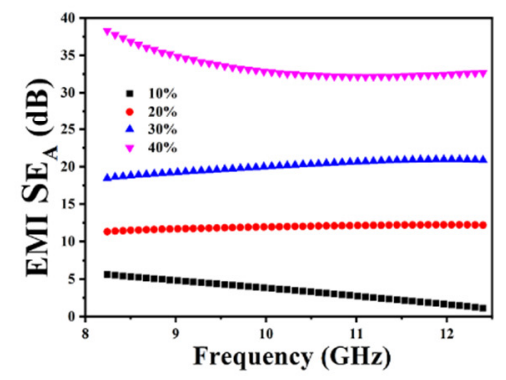

(b)

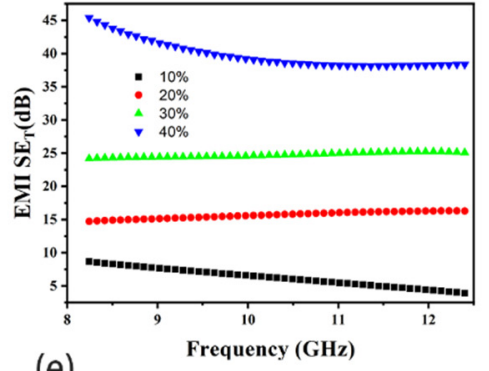

(e)

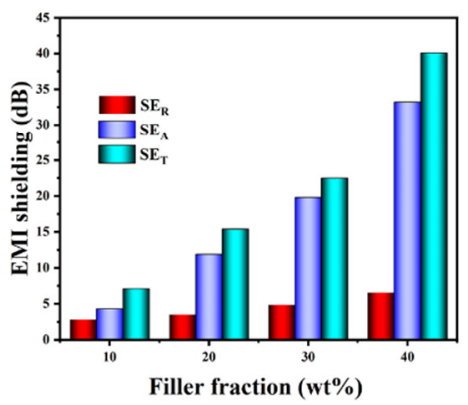

(c)

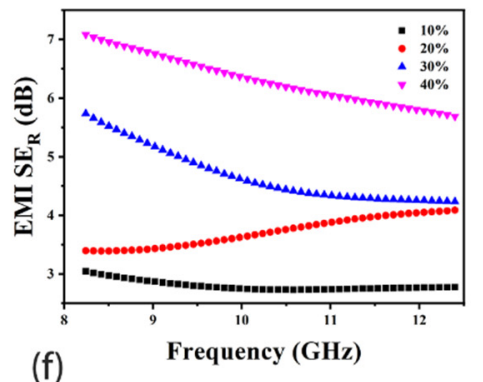

(f)

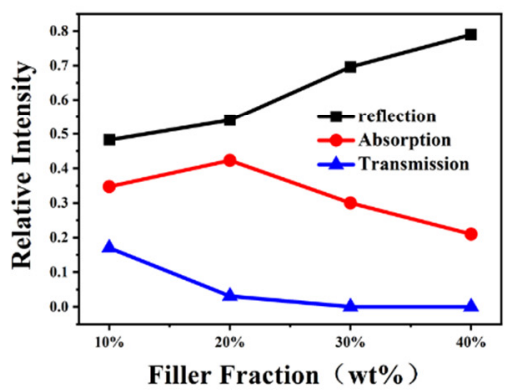

Figure 7. The electrical conductivity (a), EMI SET (b), EMI SER (c), EMI SEA (d) of GnPs@Ni/PPSU composites; EMI SE of the composites as a function of volume fraction at $9 \mathrm{GHz}(\mathbf{e})$; reflection coefficient (R), absorption coefficient (A), and transmission coefficient $(\mathrm{T})$ at $9 \mathrm{GHz}$ of the developed composites (f). The thickness of all samples was $2 \mathrm{~mm}$.

\subsection{Thermal Analysis of the GnPs@Ni-MWCNTs/PPSU Composites}

The coefficient of thermal expansion (CTE) of materials reflects the parameter of dimensional stability of materials as temperature changes. When aerospace materials and electronic devices are used in extreme conditions, such as large temperature difference between day and night, different components may have uneven volume expansion, resulting in huge internal stress and low accuracy [12]. Reducing the CTE coefficient of materials is helpful to solve the problem of size mismatch between different components in precision components after heating. Figure 8a comparatively shows the coefficient of thermal expansion of pure PPSU and the prepared composites containing different amounts of GnPs@Ni. The CTE value of pure PPSU resin was $92.3 \times 10^{-6} \mathrm{~K}^{-1}$. It is noticed that the CTE value was significantly reduced with the fillers loading ranging from $10 \mathrm{wt} \%$ to $40 \mathrm{wt} \%$. When the filling amount is $40 \mathrm{wt} \%$, the thermal expansion coefficient was $39.4 \times 10^{-6} \mathrm{~K}^{-1}$, decreasing by $57.3 \%$ compared to that of pure PPSU. The reasons for the decrease of the coefficient of thermal expansion are as follows. The results show that the filler particles can effectively restrain the chain movement of the polymer at high temperature; $\mathrm{GnPs} @ \mathrm{Ni}$, as an inorganic filler, has a polar linear coefficient of thermal expansion, so the total volume change rate of the composite decreases when heated [32]. The glass transition reflects the inherent properties of amorphous polymers and shows the long chain movement of polymers on the macro level. The addition of fillers will affect the chain segment movement of polymer molecules and the melting behavior of PPSU resin. Therefore, it has a great influence on the temperature of material and the processing and production. In Figure 8b, the differential scanning calorimetry (DSC) curves revealed that the glass transition temperatures $\left(\mathrm{T}_{\mathrm{g}}\right)$ of fabricated composites were generally elevated with the increasing content of $\mathrm{GnPs} @ \mathrm{Ni}$. It can be seen that in the GnPs@Ni/PPSU-10 wt\% composite it has increased up to $264.7^{\circ} \mathrm{C}$ with respect to PPSU $\left(221.9^{\circ} \mathrm{C}\right)$. The phenomenon was caused by the fact that, with the addition of GnPs increasing, the packing particles 
could effectively restrain the chain movement of polymer via physical constraints, so the movement of polymer chain segment required more energy.
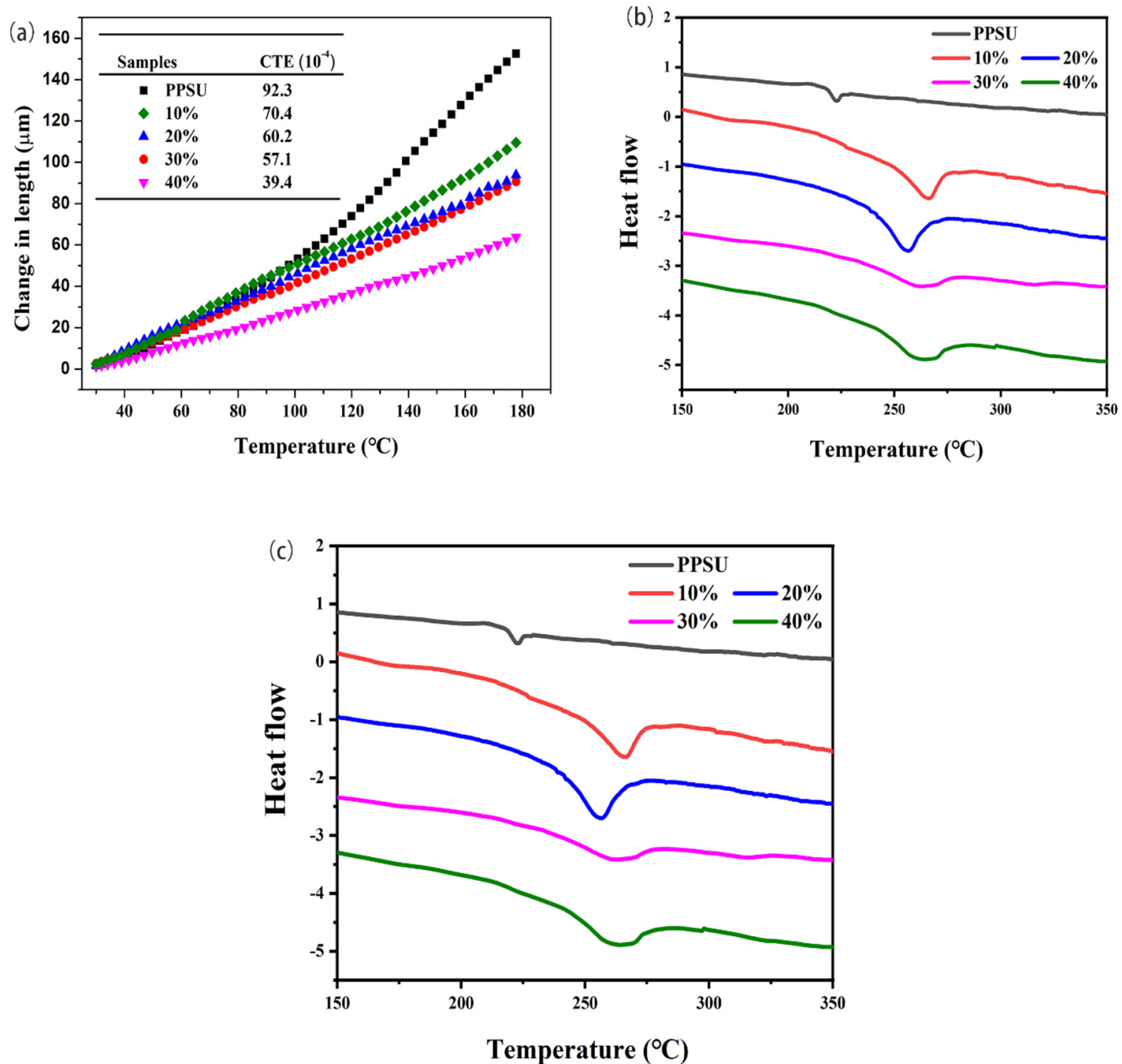

Figure 8. Coefficient of thermal expansion of pure PPSU resin and the GnPs@Ni-MWCNTs/PPSU nanocomposites (a); thermal properties of PPSU and the GnPs@Ni-MWCNTs/PPSU composites: DSC (b) and TGA (c) thermograms.

For the sake of exploring the thermostability of the prepared composites, thermogravimetry (TG) test was carried out and the results are shown in the Figure 8c. All the composites mainly presented a similar thermal weightlessness platform, corresponding to the decomposition of the main chain of PPSU. All of the fabricated composites exhibited outstanding thermostability, with high thermal decomposition temperatures of more than $500{ }^{\circ} \mathrm{C}(\mathrm{T} 5 \%)$. In addition, the thermal stability of composite material is equivalent to that of pure resin, and the $10 \mathrm{wt} \%$ thermal decomposition temperature is approximately beyond $524{ }^{\circ} \mathrm{C}$, which indicates that introduction of GnPs@Ni enhanced the thermal decomposition stability of the material. Importantly, it also showed to slow the decomposition process and higher residual char. Especially, the composite residue will be nearly $75 \%$ at $40 \mathrm{wt} \%$ filler loading. The obvious enhancement in thermal stability is attributed to the high thermal conductivity of graphene and the good interface bonding between the fillers and the matrix [39]. As a consequence, the increase in heat transfer capacity between the chain segments and the PPSU could reduce the heat storage in the composite [40]. In addition, the 
improvement of $\mathrm{T} 5 \%$ and $\mathrm{T} 10 \%$ is the result of the strong shielding effect of GnPs, which significantly delayed the escape of the degradation products of PPSU, and the thermal stability of the composite was improved [32,41].

\section{Conclusions}

The surface of graphite nanoplatelets was modified via non-covalent method by electroless plating. Pd particles were used as an autocatalytic active center to promote the formation of Ni-P alloy and Ni particles in electroless nickel plating. The nickel coating was evenly distributed on the surface of nano graphite. The GnPs@Ni/PPSU composites showed excellent thermal conductivity. The in-plane and through-plane thermal conductivity can reach $2.7 \mathrm{Wm}^{-1} \mathrm{~K}^{-1}$ and $3.7 \mathrm{Wm}^{-1} \mathrm{~K}^{-1}$, respectively, at $40 \mathrm{wt} \% \mathrm{GnPs} @ \mathrm{Ni}$ filler loading, which is 10 and 14 times higher than that of pure PPSU. The XRD diffraction patterns and SEM images illustrated that layered GnPs@Ni tended to distribute along the horizontal direction of polymer matrix. Furthermore, the composite material has good conductivity of $128 \mathrm{~S} / \mathrm{m}$ and electromagnetic interference effectiveness, and it is an electromagnetic shielding material based on reflection. The maximum EMI SE of the material can reach $42.9 \mathrm{~dB}$ when the filling amount is $40 \mathrm{wt} \%$. In addition, the composites had lower CTE, higher $\mathrm{T}_{\mathrm{g}}$ and superior thermal decomposition ability. Overall, the materials had potential applications in the fields of thermal management and electromagnetic shielding interference at high temperatures.

Author Contributions: Conceptualization, Z.C.; Data curation, Z.C. and L.C.; Funding acquisition, J.M.; Investigation, L.C.; Project administration, T.Y. and J.M.; Supervision, J.M.; Writing-original draft, Z.C.; Writing - review \& editing, T.Y. All authors have read and agreed to the published version of the manuscript.

Funding: This research received no external funding.

Institutional Review Board Statement: Not applicable.

Informed Consent Statement: Not applicable.

Data Availability Statement: The data presented in this study are available on request from the corresponding author.

Conflicts of Interest: The authors declare no conflict of interest.

\section{References}

1. Qin, M.; Feng, Y.; Ji, T.; Feng, W. Enhancement of cross-plane thermal conductivity and mechanical strength via vertical aligned carbon nanotube@graphite architecture. Carbon 2016, 104, 157-168. [CrossRef]

2. Balandin, A.A. Thermal properties of graphene and nanostructured carbon materials. Nat. Mater. 2011, 10, 569-581. [CrossRef]

3. Liang, Q.; Yao, X.; Wang, W.; Liu, Y.; Wong, C.P. A three-dimensional vertically aligned functionalized multi-layer graphene architecture: An approach for graphene -based thermal interfacial material. ACS Nano 2011, 5, 2392-2401. [CrossRef] [PubMed]

4. Sun, R.; Zhang, H.B.; Liu, J.; Xie, X.; Yang, R.; Li, Y.; Hong, S.; Yu, Z.Z. Highly conductive transition metal carbide/carbonitride (MXene)@ polystyrene nanocomposites fabricated by electrostatic assembly for highly efficient electromagnetic interference shielding. Adv. Funct. Mater. 2017, 27, 1702807. [CrossRef]

5. Zhang, H.; Zhang, G.; Gao, Q.; Tang, M.; Ma, Z.; Qin, J.; Wang, M.; Kim, J.-K. Multifunctional microcellular PVDF/Ni-chains composite foams with enhanced electromagnetic interference shielding and superior thermal insulation performance. Chem. Eng. J. 2020, 379. [CrossRef]

6. Badakhsh, A.; Lee, Y.-M.; Rhee, K.Y.; Park, C.W.; An, K.-H.; Kim, B.-J. Improvement of thermal, electrical and mechanical properties of composites using a synergistic network of length controlled-CNTs and graphene nanoplatelets. Compos. Part B Eng. 2019, 175, 107075. [CrossRef]

7. Shen, X.; Wang, Z.Y.; Wu, Y.; Liu, X.; He, Y.B.; Zheng, Q.B.; Yang, Q.H.; Kang, F.Y.; Kim, J.K. A three-dimensional multilayer graphene web for polymer nano-composites with exceptional transport properties and fracture resistance. Mater. Horiz. 2018, 5, 275-284. [CrossRef]

8. Novoselov, K.S.; Fal'ko, V.I.; Colombo, L.; Gellert, P.R.; Schwab, M.G.; Kim, K. A roadmap for graphene. Nature 2012, 490, 192-200. [CrossRef]

9. Pan, C.; Kou, K.; Zhang, Y.; Li, Z.; Wu, G. Enhanced through-plane thermal conductivity of PTFE composites with hybrid fillers of hexagonal boron nitride platelets and aluminum nitride particles. Compos. Part B Eng. 2018, 153, 1-8. [CrossRef] 
10. Yuan, H.-C.; Lee, C.-Y.; Tai, N.-H. Extremely high thermal conductivity of nanodiamond-polydopamine/thin-layer graphene composite films. Compos. Sci. Technol. 2018, 167, 313-322. [CrossRef]

11. Tang, X.-H.; Li, J.; Wang, Y.; Weng, Y.-X.; Wang, M. Controlling distribution of multi-walled carbon nanotube on surface area of Poly ( $\varepsilon$-caprolactone) to form sandwiched structure for high-efficiency electromagnetic interference shielding. Compos. Part B Eng. 2020, 196, 108121. [CrossRef]

12. Huang, X.Y.; Zhi, C.Y.; Jiang, P.K.; Dmitri, G.; Yoshio, B.; Toshikatsu, T. Polyhedral Oligosilsesquioxane-Modified Boron Nitride Nanotube Based Epoxy Nanocomposites: An Ideal Dielectric Material with High Thermal Conductivity. Adv. Funct. Mater. 2013, 23, 1824-1831. [CrossRef]

13. Zhou, W.; Zuo, J.; Ren, W. Thermal conductivity and dielectric properties of Al/PVDF composites. Compos. Part A Appl. Sci. Manuf. 2012, 43, 658-664. [CrossRef]

14. Rivière, L.; Lonjon, A.; Dantras, E.; Lacabanne, C.; Olivier, P.; Gleizes, N.R. Silver fillers aspect ratio influence on electrical and thermal conductivity in PEEK/Ag nanocomposites. Eur. Polym. J. 2016, 85, 115-125. [CrossRef]

15. Sun, W.; Chen, G.; Zheng, L. Electroless deposition of silver particles on graphite nanosheets. Scr. Mater. 2008, 59, 1031-1034. [CrossRef]

16. Xiao, W.; Lei, Y.; Xia, Z.; Chen, X.; Han, Y.; Nie, J. Effect of silver plating time on the properties of conductive silicone rubber filled with silver-coated carbonyl nickel powder. J. Alloys Compd. 2017, 724, 24-28. [CrossRef]

17. Palaniappa, M.; Babu, G.V.; Balasubramanian, K. Electroless nickel-phosphorus plating on graphite powder. Mater. Sci. Eng. A 2007, 471, 165-168. [CrossRef]

18. Li, L.; Jin, Y.; Wang, Z.Y.; He, Q.X.; Chen, R.; Wang, J.T.; Wu, H.; Zhao, X.; Mu, J.X. Preparation and characterisation of nickel-plated carbon fi-bre/polyether ether ketone composites with high electromagnetic shielding and high thermal conductivity. Colloid Polym. Scince 2019, 297, 967-977. [CrossRef]

19. Chen, X.; Wang, X.; Li, L.; Qi, S. Preparation and microwave absorbing properties of nickel-coated carbon fiber with polyani-line via in situ polymerization. J. Mater. Sci. Mater. Electron. 2016, 27, 5607. [CrossRef]

20. Huang, X.; Qi, X.Y.; Freddy, B.; Hang, H. Graphene-based composites. Chem. Soc. Rev. 2012, 41, 666-686. [CrossRef]

21. Liu, Y.; Wu, K.; Luo, F.; Lu, M.; Xiao, F.; Du, X.; Zhang, S.; Liang, L.; Lu, M. Significantly enhanced thermal conductivity in polyvinyl alcohol composites enabled by dopamine modified graphene nanoplatelets. Compos. Part A Appl. Sci. Manuf. 2018, 117, 134-143. [CrossRef]

22. Liu, Z.; Chen, Y.; Dai, W.; Wu, Y.; Wang, M.; Hou, X.; Li, H.; Jiang, N.; Lin, C.T.; Yu, J.H. Anisotropic thermal conductive properties of cigarette fil-ter-templated graphene/epoxy composites. RSC Adv. 2018, 8, 1065-1070. [CrossRef]

23. Yang, K.; Gu, M. Enhanced thermal conductivity of epoxy nanocomposites filled with hybrid filler system of triethylenetetramine-functionalized multi-walled carbon nanotube/silane-modified nano-sized silicon carbide. Compos. Part A 2010, 41, 215-221. [CrossRef]

24. Zhang, S.; Li, X.; Guan, X.; Shi, Y.; Wu, K.; Liang, L.; Shi, J.; Lu, M. Synthesis of pyridine-containing diamine and properties of its polyi-mides and polyimide/hexagonal boron nitride composite films. Compos. Sci. Technol. 2017, 152, 165-172. [CrossRef]

25. Xu, Y.; Yang, Y.; Duan, H.; Gao, J.; Yan, D.-X.; Zhao, G.; Liu, Y. Flexible and highly conductive sandwich nylon/nickel film for ultra-efficient electromagnetic interference shielding. Appl. Surf. Sci. 2018, 455, 856-863. [CrossRef]

26. Li, J.; Wang, A.; Qin, J.; Zhang, H.; Ma, Z.; Zhang, G. Lightweight polymethacrylimide@copper/nickel composite foams for electromagnetic shielding and monopole antennas. Compos. Part A Appl. Sci. Manuf. 2020, 140, 106144. [CrossRef]

27. Su, Z.; Wang, H.; Tian, K.; Huang, W.; Xiao, C.; Guo, Y.; He, J.; Tian, X. The combination of $\pi-\pi$ interaction and covalent bonding can synergistically strengthen the flexible electrical insulating nanocomposites with well adhesive properties and thermal conductivity. Compos. Sci. Technol. 2018, 155, 1-10. [CrossRef]

28. Su, Z.; Wang, H.; Tian, K.; Huang, W.; Guo, Y.; He, J.; Tian, X. Multifunctional anisotropic flexible cycloaliphatic epoxy resin nanocomposites reinforced by aligned graphite flake with non-covalent biomimetic functionalization. Compos. Part A Appl. Sci. Manuf. 2018, 109, 472-480. [CrossRef]

29. Yuan, G.; Li, X.; Dong, Z.; Westwood, A.; Cui, Z.; Cong, Y.; Du, H.; Kang, F. Graphite blocks with preferred orientation and high thermal conductivity. Carbon 2012, 50, 175-182. [CrossRef]

30. Zhou, S.X.; Zhu, Y.; Du, H.D.; Li, B.H.; Kang, F.-Y. Preparation of oriented graphite/polymer composite sheets with high thermal conductivities by tape casting. New Carbon Mater. 2012, 27, 241-249. [CrossRef]

31. Tanimoto, M.; Yamagata, T.; Miyata, K.; Ando, S. Anisotropic Thermal Diffusivity of Hexagonal Boron Nitride-Filled Polyimide Films: Effects of Filler Particle Size, Aggregation, Orientation, and Polymer Chain Rigidity. ACS Appl. Mater. Interfaces 2013, 5, 4374-4382. [CrossRef] [PubMed]

32. He, Q.X.; Chen, R.; Li, S.; Wang, Z.Y.; Wen, F.Y.; Wang, B.H.; Mu, J.X. Excellent thermally conducting modified graphite nanoplatelets and MWCNTs/poly(phenylene sulfone) composites for high-performance electromagnetic interference shielding effectiveness. Compos. Part A 2021, 143, 106280. [CrossRef]

33. Jiang, Y.; Liu, Y.; Min, P.; Sui, G. BN@PPS core-shell structure particles and their 3D segregated architecture composites with high thermal conductivities. Compos. Sci. Technol. 2017, 144, 63-69. [CrossRef]

34. Fu, C.; Yan, C.; Ren, L.; Zeng, X.; Du, G.; Sun, R.; Xu, J.; Wong, C.-P. Improving thermal conductivity through welding boron nitride nanosheets onto silver nanowires via silver nanoparticles. Compos. Sci. Technol. 2019, 177, 118-126. [CrossRef] 
35. Kumar, P.; Shahzad, F.; Hong, S.M.; Koo, C.M. A flexible sandwich graphene/silver nanowires/graphene thin film for highperformance electromagnetic interference shielding. RSC Adv. 2016, 6, 101283-101287. [CrossRef]

36. Xu, Y.; Li, Y.; Hua, W.; Zhang, A.; Bao, J. Light-Weight Silver Plating Foam and Carbon Nanotube Hybridized Epoxy Composite Foams with Exceptional Conductivity and Electromagnetic Shielding Property. ACS Appl. Mater. Interfaces 2016, 8, $24131-24142$. [CrossRef]

37. Liu, S.; Qin, S.H.; Song, P.A.; Jiang, Y.; Wang, H. Lightweight high-performance carbon-polymer nanocomposites for electromagnetic inter-ference shielding. Compos. Part A Appl. Sci. Manuf. 2021, 145, 106376. [CrossRef]

38. Lee, Y.; Liu, Y.; Park, M.; Kim, H.Y. Ultrahigh electromagnetic interference shielding performance of lightweight, flexible, and highly conductive copper-clad carbon fiber nonwoven fabrics. J. Mater. Chem. C 2017, 5, 7853-7861. [CrossRef]

39. Xue, Y.; Li, X.; Wang, H.; Zhao, F.; Zhang, D.; Chen, Y. Improvement in thermal conductivity of through-plane rubber composites. Mater. Des. 2019, 165, 2482-2493. [CrossRef]

40. Wu, K.; Chang, Y.; Yang, C.; Gung, Y.; Yang, F. Synthesis, infrared stealth and corrosion resistance of organically modified silicate-polyaniline/carbon black hybrid coatings. Eur. Polym. J. 2009, 45, 2821-2829. [CrossRef]

41. Yousefi, N.; Sun, X.; Lin, X.; Shen, X.; Jia, J.; Zhang, B.; Tang, B.; Chan, M.; Kim, J.-K. Highly Aligned Graphene/Polymer Nanocomposites with Excellent Dielectric Properties for High-Performance Electromagnetic Interference Shielding. Adv. Mater. 2014, 26, 5480-5487. [CrossRef] [PubMed] 